\title{
Neuromarketing: The New Science of Advertising
}

\author{
Sunita Kumar \\ Department of Management Studies, Christ University, India
}

Copyright $(2015$ by authors, all rights reserved. Authors agree that this article remains permanently open access under the terms of the Creative Commons Attribution License 4.0 International License

\begin{abstract}
Advertisers today spend most of their time in understanding the science to peer into consumers' minds. Today Neuromarketing has given them the power to delve into our subconscious mind. It is always very difficult for a marketer to understand the customer mind set. How a customer selects a particular product or service, where they look for information and how they search for it. To investigate how attention levels influence users, this conceptual paper makes use of Neuromarketing as a tool to measure the level of attention that results from advertisement exposure and explores how different levels of attention influence users in conscious and unconscious ways.
\end{abstract}

Keyword Advertising, Eye-tracking, Neuromarketing, Influence

\section{Introduction}

As we know Marketing is a: "Social and managerial process by which individuals and organizations obtain what they need and want through creating and exchanging products and value with each other" Kotler, Armstrong et al. [24]. Earlier the functions of marketing included advertising, selling and distribution but in today's context, marketing has witnessed tremendous growth. In the current scenario with the emergence and the use of other academic areas like social sciences, psychology, sociology, mathematics, economics and more recently neurosciences, marketing has evolved and is recognized as a more comprehensive science. Contemporary approaches give different dimensions of marketing such as: relationship marketing (where customer has the lead role), business marketing, and social marketing (where society benefits are what matters) as per Adcock, Halborg et al. [2]. With the current decline of the power of advertising and rising competition amongst brands, the new marketing challenge is to create consumer value while receiving value in return according to Engel, Blackwell et al. [8].

According to Philip Kotler [24], "Marketing is a subject that is easy to pretend to understand but difficult to practice ". The objective of all marketing communication is to enhance purchase. Advertising is one of the important components of the promotional mix; billions of dollars are spent every year on advertising. Whether such advertising is effective or not is still a question? At the same time it is difficult to measure actual effectiveness of an advertisement. Advertisers hope that buying will eventually happen as a product of their advertising efforts. Consumers on the other hand may simply think of advertisements as a good source of entertainment. Even before the conceptualization of the advertisement, market research companies conduct relevant activities and based on their findings only do they go ahead with a given piece of an advertisement. However, money spent on design and release of marketing communication, notwithstanding all the preparatory research, may still not ensure the desired results.

Charles young in his book "The Advertising Research Handbook says " This is perhaps the prime reason why the researches, the world over, have started questioning the very premises on which responsible -for-marketing communications-people base their assumptions, judgements and research." What he is trying to say is that, marketing research has started questioning the premise that a target consumer will reflect his/her true thoughts in response to a questionnaire. Assuming that the consumer does not reflect his/her true feelings regarding a product/service, how can we rely on the derived conclusions? "Respondents may be unwilling because they feel the information is embarrassing or private. For example, they may realize that their reason for using designer jeans is the jeans make them feel socially accepted-in style. They may cope either by not answering (or more frequently) by providing rationalizations that appear logical. They might focus upon quality of workmanship, fit, price and / or style even though such considerations are in fact secondary." David A. Aaker [1].

All this research reveals that sometimes the consumers themselves may not be aware of what their true feelings are in a given situation. In order to prove this point, we can take the example of Dettol vs Savlon. Savlon was clinically proven to be a better antiseptic than Dettol. Even though it was backed by Johnson \&Johnson, for having advantages like better fragrance and non-stinging properties, it miserably failed in the Indian market. In this case the market research had indicated that by incorporating the said 
advantages, the product would be a success. However the consumer reaction was the exact opposite. This example clearly evidentiates that consumers aren't necessarily aware of what they feel.
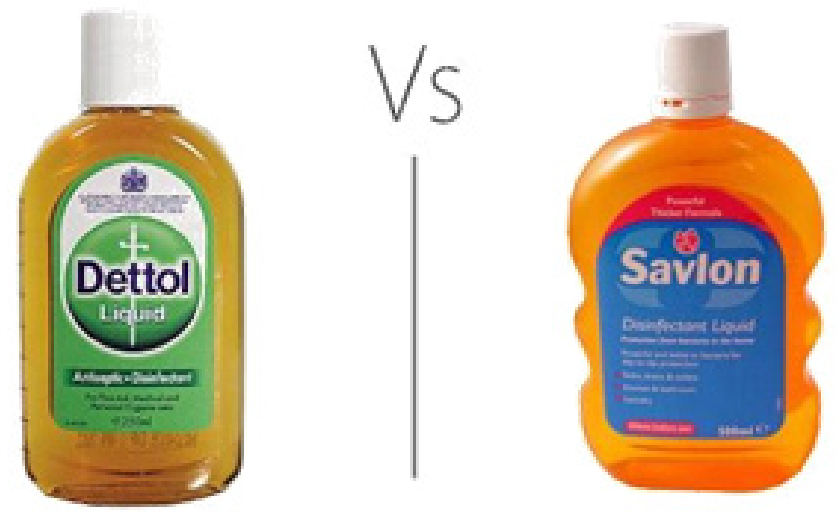

Source:

http://idyeah.com/blog/wp-content/uploads/2012/02/dettol-savlon.jpg

Figure 1. Dettol vs Savlon

Several reasons supported the adoption of the 'behaviourist model' by the advertising fraternity. The same are as follows:

- It was a probable explanation to how human beings react to advertisements.

- It was relatively simpler to understand and explain to advertisers how their advertising would work.

- It leads to the emergence of a rational approach like the AIDA concept for predicting the success of advertisements before they were actually aired.

- It reinforced the idea that all the brand decisions are conscious and rational and advertising can affect such consciousness.

However, all these assumptions ignore the existence of knowledge on how consumers think and how the information is processed in our minds. The human brain is the most complex organ that co-ordinates, monitors, and controls our activities. Since the mechanism of the brain is a mystery in so many of its functional aspects, which are yet to be decoded, it is impossible to fully understand it. This is responsible rise of Neuromarketing, the field that has unprecedented potential of showing the path to profitable branding and advertising business.

\section{What Is the Brain's Function in Layman Terms?}

The philosopher Plato compared the human soul to a chariot with two horses, that of emotion and reason. He suggested that human behaviour has an emotional element to it. However, the horse of logic or reason has prevailed over emotion for centuries and is thus used to explain human behaviour as per Economist [7].

Paul McLean, a neurologist, suggested a model of the human brain (Figure 2) composed of three imbricate structures, each specialized in certain functions:

- $\quad$ The primitive or the $R$ complex (reptilian) brain -is that part of the brain that acts as a quick decision maker. This acts in situation of survival or a typical situation in which strong urge to act (may be right or wrong) required.

- The emotional or the limbic brain -This is active in emotional aspects of the day today social life. Because of this we often feel happy, sad, excited, dejected, cool, calm and so on.

- Rational or Neo-cortex brain -This is the analytical brain. It solves the problems at hand. It uses logic, creates rational memories and allows innovative thinking. This brain takes its own time and does not decide in the spur of the moment.

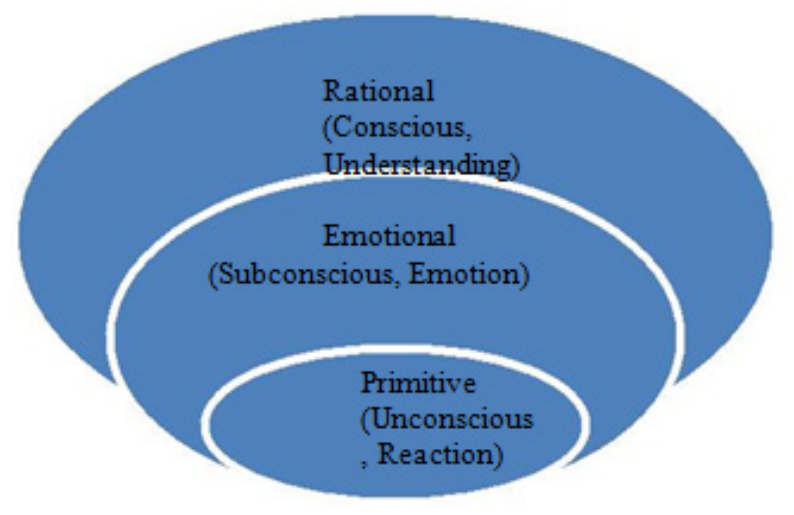

Figure 2. Model of the human brain

To be effective, advertisers initially need to target the emotional brain and then the primitive brain, which leads them to open the channel of attention - which then transmits information to the rational brain. Many researchers assumed that nonverbal, holistic, and pictorial images were stored and processed on the right side of the brain.

\section{Neuromarketing the New Science of Marketers}

The word "Neuromarketing" (NM) is a recently developed concept. The Economist [7] credits Jerry Zaltman with proposing the union of brain-imaging technology with marketing in the late 1990s. When the Atlanta based marketing firm, BrightHouse, opened a Neuromarketing division in 2001, the synthesis of various related techniques of neuroscience and marketing started to attract scientists, businessmen, and journalists on one platform. Initially, the whole research was kept confidential and continued in collaboration with selected companies (L-mart, Coca-Cola, Levi-Strauss, Delta Airlines, Ford etc.) interested in the possible outcome of Neuromarketing.

Neuromarketing is defined as a new branch of marketing that makes use of technology to determine a consumer's internal, subconscious reaction to products and brand names 
in order to plan effective marketing strategies. Based on the resultant techniques derived from neurosciences better identification and understanding of cerebral mechanisms fundamental to consumer's behaviour is possible. This is helpful in the prospect of increasing the efficiency of the commercial actions of companies.

Neuromarketing is a branch of the general field of neuroeconomics, which is an interdisciplinary field that combines economics, neuroscience and psychology, to study the functioning of the brain in decision-making situations according to Kenning and Plassmann [23].

Neuroscience intends to gather knowledge about the structure and function of the brain. A specific branch of neuroscience is cognitive neuroscience that attempts to understand the neural mechanisms behind processes like reasoning, emoting, memory, decision making, and so on. This field when applied in marketing can help in brand positioning, hierarchy of effects, and brand loyalty according to Perrachione and Perrachione [38]. Using techniques and advancements in neuroscience, researchers can now obtain information about human brain's response to marketing stimuli according to P. Renvoisé and Morin [43], without simply relying on subjective reports given by the participant according to Kenning [23]

Coy [3], mentions that that neurology is more about looking for economic gain or loss from an emotional angles. The decision to buy now or later "can be as impulsive as chimps".

Neuromarketing suggests that both emotional thinking and rational thinking co-exist and are interdependent. Similarly neuroeconomics defies the notion that emotions can hamper economic decision making. Emotions get people's attention and focus the rational brain on the matter under consideration. This may lead to satisfaction or dissatisfaction, and both satisfaction and dissatisfaction are short lived phenomenon. There have been multiple surveys suggesting that even satisfied customers walk away from the firm and dissatisfied may return after some time. This happens on regular basis. The detailed explanation to this puzzle may lie inside our brain. The potential of Neuromarketing in reducing marketing failures and increasing marketing successes seems to be quite positive; although not without accompanying negativity.

Various methods have been put in place to test the new advertising campaigns. These methods are surveys, road shows and focus group discussions. As per brain scanning, the brain needs to be monitored while watching the advertisement, whichever area of the brain responses or lights up, indicates the subject's unconscious thought patterns. This must match with the intent of the advertisement, example- passion, excitement, humour, hostility etc.; if the brain area is unresponsive then the advertisement has failed the test. Unfortunately, these results can only indicate activation correlated with different images but cannot tell us anything about why such discrepancies exist. There is no direct link between arousal and behaviour; the purchase intent as such is immeasurable. As James [22] says, "The only time a human being cannot help acting on arousal is as a toddler."

Harris [15] mentions that there are many companies who have made use of this technique to test their advertisements. For example: The Ford Motor and Unilever.

Table 1. Various company and respective application

\begin{tabular}{|c|c|c|}
\hline Company & Application & Industry \\
\hline Procter \& Gamble & In launching of Febreze, room freshener & FMCG \\
\hline Motorola & Product-designing & Mobile Manufacturing \\
\hline Delta Airline & To gain benefit out of fabulous experience & Airlines \\
\hline Hyundai & In changing exterior appearance of the car & Automobile \\
\hline Frito Lay & To test commercials, products and packages as well as to learn & Food \\
\hline (PepsiCo) & how to appeal better to women & IT/ITES \\
\hline Yahoo & To test pre-release effectiveness of its branding campaign & IT/ITES \\
\hline $\begin{array}{c}\text { Paypal(along with } \\
\text { ebay) }\end{array}$ & To identify speed and security issues of e-shopping & IT/ITES \\
\hline Microsoft & To know engagement of Xbox users while playing the game, including their feelings of \\
\hline Buick Motors & In enhancing dealers' experience with customers & Automobile \\
\hline Google & To measure effectiveness of YouTube overlays versus prerolls and found that overlays & ITere much more effective with Subjects \\
\hline The Weather Channel & To measure viewer reactions to three different promotional pitches for a popular series & Television \\
\hline
\end{tabular}

Source: Babu and Vidyasagar (2012) 
Dr. Gemma Calvert (Chairperson of Applied Neuro imaging at the University of Warwick, England) and team researched on a number of smokers and the findings were amazing. We know that in most countries cigarette packages come with inscribed warnings of cancer. These warning are either printed or depicted via pictures. As per Lindstorm [26], 10 million cigarettes are sold every minute. Dr. Calvert researched as to why people purchase cigarettes even though the warning is visible to them. To find out the discrepancies, he not only surveyed but used the technique of Neuro imaging to understand the thought processes bubbling within the brain. During the survey most of the participants indicated that warning message definitely acts as deterrent. On the contrary the brain imaging (fMRI) findings suggested that the brain did not focus much on warning labels and failed to deter the use of the cigarettes. This finding was surprising to many people including participants. It also raised the question of money spent on warning messages.

All of us can recollect the burning sensation when shampoo would go in our eyes. It was very common in childhood and is still frequent in little children. That is why many brands of kid shampoos still highlight this feature as opposed to other in their advertisements.

Techniques used for Neuromarketing studies:

(These definitions have been taken from different sources mentioned in References section)

fMRI(Functional magnetic resonance imaging) is a medical procedure to measure the brain's activity by detecting the oxygen level in blood flow. When a brain area is more active it requires more oxygen.

MRI - Magnetic Resonance Imaging (This technology is used for detecting brain tumors). It also helps in understanding the manner in which the human brain interprets processes and understands messages transmitted by the advertising content. Which is why Neuromarketing focuses on what attributes (the look and feel) of the product must be decided by the end user.

EEG (Electroencephalography) measures and records the electrical activity of the brain.

SST (Steady State Topography)measures and records the brain's activity. Its high temporal resolution makes it possible to use SST in Neuromarketing tests concerned with TV advertisements.

MEG (Magnetoencephalography) offers information about the brains activity by using a magnetic field. It is a direct measure of the brain's activity, unlike functional measures as fMRI. It has high temporal and spatial resolution.

Respiratory rate means the number of breaths usually taken during one minute.

Heart rate means the number of heartbeats that occur during one minute.

According to www.esomar.org pupilometer is "a device used to measure the dilation of a participant's pupil in response to a visual stimulus".

Galvanic skin response or skin conductance measures the changes in the electrical properties of the skin, depending on the level of moisture.

Eye tracking method, tracks what the eyes are focusing at.

Voice analysis records the psychophysiological stress responses that come across in human voice owing to the response of the vocal cords to such stress.

\section{Use of Eye tracking: The New Technique of Neuromarketing}

Half of the money spent on advertising is wasted but advertisers are unaware of it. It has been hard for advertisers to figure out what works and what doesn't. Innovative technologies that aid the study of intricacies related to consumer behaviour are being pioneered, and their findings are being sold to companies that hope to use their advertising budgets more wisely. One company that does Eye tracking conducts extensive research on how consumers view advertisements so that their clients can design advertisements for maximum incidental impact on their target audience.

\section{How Eye Tracking Works}

By making use of a lightweight headset with three cameras, it is possible to record exactly where a person is looking as he or she is exposed to some kind of visual display. For example, a person is navigating through a website, looking to purchase an item. With eye tracking it is possible to mark exactly where the person is looking for specific information about the item, how they compare different items, and where they look to navigate to the shopping cart or other areas of the site.

The user's point of gaze is superimposed on a video recording of the website as they interact with it. In this way, it is possible for developers to interact with the interface through the eyes of the user. It is possible to gauge objectively if a user has difficulty in locating information. The eye patterns can also be plotted on a bitmap in order to analyse the viewing history spanning several seconds or longer. Gaze Traces ${ }^{\mathrm{TM}}$ document the scanning behaviour of a single participant scanning a single screen display or portion of it. This allows you to see clearly what on the page first caught the attention of the user, what elements he missed, and what elements may have been confusing.

The eye tracking company analyses television, internet, and web page viewing, packaging, and even brand positioning for sponsorships and then delivers suggestions to their clients on how to optimally capture the attention of target audiences. The company also claims that it can assess customer's emotional reactions to an advertised product.

The Poynter institute declared research observations made while studying the eye movements of web suffers ,they assessed whether advertisements get viewed specifically or not as a result of page placement and several specific design elements. Some of the findings seemed obvious, such as the fact that $55 \%$ of the viewers scanned an advertisement 
placed on top of the page, while only $14 \%$ saw on the bottom.

Some surprising findings were as follows:

- Text advertisements were more effective than graphic advertisements.

- Advertisements that blended into the content generally did much better; for example advertisements inserted into text columns did extremely well.

- Visual breaks between content sections tend to act as a visual dams, creating a high drop-off rate for further viewing

\section{Campbell Soup' Neuromarketing Initiative}

In 2005, market researchers at Campbell conducted a study to assess the customers recall rate of Campbell soup's as a result of their advertising efforts, and their influence on the purchase decision of customers. To their surprise, they discovered that the company's advertisements (that seemed to be relevant in consumer surveys) were never really effective in generating sales. An advertisement is effective, when it is " ... seen, read, believed, remembered and acted upon." However, they discovered that the consumers did not think much about Campbell soup and also found out that their buying instinct was dying down whenever they saw a Campbell product at the supermarket soup aisle.

The company decided to use Neuromarketing techniques to expose the factors that prompt consumers to decide on buying a soup, so that new label design would enhance the sale of the soup.

On behalf of Campbell, Inner scope Research interviewed 40 consumers at two different places, i.e., at their homes and later at grocery stores. During these interviews, the customers relayed that the can's label portraying the soup did not look warm and the big spoon holding a sample of soup did not provoke any emotional response from them.

In the next phase of research, during their visit to the stores, the 40 consumers were clipped with small video cameras at eye level to track eye movements and pupil width. The customers were allowed to watch their video-footage when they were shopping for soup. The eye movement and pupil width showed that the consumers' interest towards Campbell soup (though emotionally attached) faded away when they faced an array of red and white soup cans on the store shelves. The other results surprised the researchers; Campbell spent two years studying the small changes that take place in human body in response to pictures of bowls of soup to logo design. These results formed the basis for guiding the company to redesign its labels.

All this findings clearly indicate how eye tracking techniques can be effectively used in advertising.

\section{Uses of Neuromarketing in Advertising}

The famous "Pepsi vs. Coca-Cola" experiment, in which scientists studied the motivation behind brand preferences, was what brought Neuromarketing into the spotlight. The researchers observed that although Pepsi and Coke are essentially identical, people often favour one over the other. They subsequently sought to investigate how cultural messages work to guide our perception of products as simple as everyday beverages.

The experiment was simple: there were two taste testsone blind and one in which subjects knew which beverage was which - and the researchers observed the corresponding brain activity. When volunteers were unaware of which brand they were drinking, the fMRI showed activation in the ventromedial prefrontal cortex, a basic "reward center," when they drank Pepsi. However, when the subjects knew which soda was which, the scans showed brain activity in the hippocampus, midbrain, and dorsolateral prefrontal cortex (which are centres for memory and emotion), in favour of Coke. So essentially, people actually liked the taste of Pepsi, but they were more inclined to believe that they preferred Coke, based on nostalgia and emotional connections. From these results, the researchers determined that "a preference for Coke is more influenced by the brand image than by the taste itself" according to BridgerD,Lewis D [4]

The outcome of these studies is intriguing and may seem even a bit entertaining; however, when given a second glance, it can also be alarming. The fact that a series of ads could actually cause your brain to believe something that contradicts what the rest of your body believes is unnerving, to say the least. Because of this, there is a growing controversy surrounding the subject of Neuromarketing.

A Forbes article indicates that all this is moving toward an elusive goal: to find a 'buy button inside the skull' and to test products, packaging and advertising for their ability to activate it.

So far, researchers are figuring out which part of the brain facilitates product recognition and choice; they are related to primal urges like those for power, sex and sustenance. As for brand loyalty, it turns out that memory and emotion plays a crucial role. 'In the not-too-distant future, firms will be able to tell precisely if an advertising campaign or product redesign triggers the brain activity and neurochemical release associated with memory and action,' predicts James Bailey, professor of organizational behaviour at George Washington University.

\section{NeuroFocus and Frito-Lay}

Frito-Lay is the company manufacturing Cheetos, the bright orange snack food found in convenience stores and supermarkets. In 2008, they worked with NeuroFocus to investigate how consumers felt about the snack, as well their response to Cheetos' messages. Using proprietary technology based on EEG, NeuroFocus reported that the orange residue left behind after eating Cheetos evoked a feeling related to enjoying a guilty pleasure. Consistent with this, the company identified a strong positive consumer response to an ad campaign that had been planned by 
traditional focus groups. Titled "The Orange Underground," the advertisement featured a mysterious version of the Cheetos cheetah mascot encouraging people to commit subversive acts. This campaign won Frito-Lay (and NeuroFocus) a Grand Ogilvy award from The Advertising Research Foundation (ARF) ${ }^{5}$

\section{Ethics Issues in Neuromarketing - Where Neuromarketing Headed?}

When information is recorded from the brain, it is easy to believe that it represents something universal about the human condition. Clearly though, such an assumption ignores much of what we know about psychological differences between cultures, and the influence of our environment on how we think. Thus, one of the major frontiers for Neuromarketing lies in building an understanding of the ways in which different societies relate to companies, advertisements and brands. This is a domain in which neuroscientific methods can shine, as they are able to advocate not just whether marketing messages are perceived differently, but whether they are actually represented differently biologically across cultures. Knowing distinctions or similarities at the level of neural responses could yield a tremendous ability for companies to tailor the way that they approach domestic and international marketing and manage their global brand. An important first step has already been taken in this direction, with the recent announcement of a collaboration between the US based Sands Research and Brain Intelligence Neuro-Consultancy Ltd. in China.

Finally, it is becoming apparent that a crucial element of progress in the field of marketing as a whole will be to combine techniques. Many individual Neuromarketing methods can answer one facet of a question very well; yet have limitations that interfere with drawing strong general conclusions. In addition, significant advances are being made with technologies that are excellent complements for neural measures, such as virtual reality environments that mimic the normal consumer experience relatively better than other simulations. The cachet of Neuromarketing may come from its "claim to the brain," but it is my opinion that these methods should enhance, rather than compete with, other types of consumer research.

\section{Conclusions}

Vicky Phan [39] "Neuromarketing is an emerging branch of neuroscience in which researchers use medical technology to determine consumer reactions to particular brands, slogans, and advertisements. By observing brain activity, researchers in lab-coats can predict whether you prefer Pepsi or Coke more accurately than you can. Critics have already begun to denounce the idea for its intrusiveness; however, though the field is already highly controversial, there is no doubt that it's continuing development will ultimately have a profound impact on consumerism and the overall study of human behaviour."

Consultants such as Martin Lindstorm also had a positive perception of Neuromarketing. He explains, "But I do not believe Neuromarketing is the insidious instrument of corrupt governments or crooked advertisers. I believe it is simply a tool, like a hammer. Yes - in the wrong hands a hammer can be used to bludgeon someone over the head, but that is not its purpose, and it does not mean that hammers should be banned, or seized, or embargoed. The same is true for Neuromarketing." Martin Lindstorm further states, "It is simply an instrument used to help us decode what we as consumers are already thinking about when we are confronted with a product or a brand - and sometimes even to help us uncover the underhanded methods marketers use to seduce and betray us without our even knowing it. It is not my intention to help companies use brain-scanning to control consumers' minds, or to turn us into robots. Sometime, in the distant future, there may be people who use this tool in the wrong way. But my hope is the huge majority wield this same instrument for good: to better understand ourselvesour wants, our drives, and our motivations - and use that knowledge for benevolent and practical purposes (And if you ask me, they'd be fools not to)".

Neuromarketing is new area and although some work has gone into it over the last 10 years. Only few experiments performed have evidentiated its ability to meet the requirement of the researcher as well as of companies. Since it is directly related with observing the functions of the human brain and strong intrusion into privacy hence ethics will be questioned every now and then. There are not many findings that suggest that conventional methods of measuring effectiveness of advertisements are profoundly beneficial or not. To conduct experiments by implementing Neuromarketing is very expensive and it will act as deterrent in the near future to those who wish to explore the area. It has also been observed that to study this field participation is required in collaboration with various streams such as Psychology, Neurology and Marketing. One other concern has been with regard to possible side effects of such procedures when experiments are conducted in the absence of medically approved authorities.

According to Pinker[40]When we talk about human brain we have to understand that the perception and self play very important roles in shaping human behavior. One's concept of oneself as well as perception, are also shaped by one's culture and belief. In fact, one of the most popular theories in intercultural communication argued that the languages we speak influence our thought and behavior and since cultures differ so widely in their language that they will also differ in the way we think and behave. For example some culture has only few color where as some culture has very vivid picture and color so their thinking and behavior will be also different based on their culture. Using culture and neuroscience one can make advertising marketing campaign more effective and interesting. 
Culture can play an exceedingly important role with regard to the behavior one exhibit, and how one perceives the world. Drawing support from Markus \& Kitayama[29] , it is logical to argue that culture can influence the interpretation of the same object/act in several different and diverse ways. From here, it is possible to connect and draw definite and conclusive evidence from the field of neuroscience in this regard. The study conducted by Freeman[10] also indicates that these cultural dispositions not only influence behavior but also brain function.

It is for a multitude of reasons that one cannot yet decide whether Neuromarketing will act as a saviour in the future or be just another marketing stint. More aggressive research under the guidance of authorities is required to actually conclude on whether this technique is simply a hoax, hype or actual hope of consumerism in the future.

\section{REFERENCES}

[1] Aakar, D.(1991). Managing Brand Equity. Capitalizing on the Value of a Brand Name. Free Press: New York

[2] Adcock, D., A. Halborg, et al. (2001). Marketing: Principles and Practice. Edinburgh Gate, Prentice Hall.

[3] Coy,p.(2005).old. smart. productive., business week 3923/253(June27),76-81.

[4] Britt, B. (2004), "Automakers tap consumer brains", Automotive News Europe, 9 (1), 1-22. Babu, S S and Vidyasagar, T P (2012), "Neuromarketing: Is Campbell in Soup?", TheIUP Journal of Marketing Management, XI(2),

[5] Camerer, C., George, L. and Drazen, P. (2004), "Neuroeconomics: why economics needs brains", Journal of Economics, 106 (3), 555-79.

[6] Eastman, D. (2006), Neuromarketing: The Application of Cognitive Neuroscience to Marketing Research, Western Kentucky University, Bowling Green, KY.

[7] Economist (2004), "Inside of the mind of the consumer", Economist, 371(8379), 12.

[8] Engel, J. F., R. D. Blackwell, et al. (1995). Consumer Behavior, Elizabeth Widdicombe.

[9] Frick, R. (2005), "Battle of the binge", Kiplinger's Personal Finance, 59(11), 72-5. Friedman, R.A. (2006), "What's the ultimate? Scan a male brain”, New York Times, 156(53743), 10 .

[10] Freeman, J. B., Rule, N. O., Adams Jr., R. B., \& Ambady, N. (2009). Culture shapes a mesolimbic response to signals

of dominance and subordination that associates with behavior. NeuroImage, 47, 353-359.

[11] Ferguson C J, Munoz M E, and Medrano M R (2012) Advertising Influences on Young Children's Food Choices and Parental Influence - Journal of Pediatrics 160, 452-457.

[12] Glimcher, P. (2003), Decisions, Uncertainty and the Brain:
The Science of Neuroeconomics, MIT Press, London.

[13] Grimes, A. (2006), "Are we listening and learning? Understanding the nature of hemispherical lateralization and its application to marketing", International Journal of Marketing Research, 48 (4), 439-60.

[14] Hansen, F. (1981), "Hemispheral lateralization: implications for understanding consumer behavior", Journal of Consumer Research, 8, June, 23.

[15] Harris, R. (2006), "Brain waves", Marketing Magazines, 111(20), 15-17.

[16] Henricks, M. (2006), "Gray matters", Entrepreneur, January, 70-3. Herman, S. (2007), "Nose news", Chemical Reaction, January, 50-1.

[17] Herman, S. (2005), "Selling to the brain", Chemical Reaction, May, 64-6.

[18] Huang, G.T. (2005), “The economics of brains”, Technology Review, May, 74-6.

[19] http://en.wikipedia.org/wiki/Triune_brain - information retrieved on Aug 3, 2013.

[20] Harris JC (2003) Social neuroscience, empathy, brain integration and neurodevelopmental disorders. Physiol Behav. $79,525-531$.

[21] Jain, A. (2010). Temptations in cyberspace: New battlefields in childhood obesity. Health Affairs, 29(3), 425-429.

[22] James, S. (2004), "Neuromarketing is no brainwave if you just think about it", Precision Marketing, Vol. 24, September, 12-13.

[23] Kenning, P. and H. Plassmann (2005). "NeuroEconomics: An overview from an economic perspective." Brain Research Bulletin 67: 343-354.

[24] Kotler, P. and K. L. Keller (2008). A framework for marketing management, Pearson Prentice Hall.

[25] Lambert KG, Gerlai R (2003) The neurobiological relevance of social behavior: Paul MacLean's legacy. PhysiolBehav, 79, 341-342.

[26] Lindstrom M (2008) Buyology - Truth and Lies About Why We Buy. Crown Business 1stEdition.

[27] Lace, S. (Ed.) (2005), The Glass Consumer: Living in a Surveillance Society, Policy Press, Bristol.

[28] Lee, N., Broderick, A. and Chamberlain, L. (2007), "What is neuromarketing? A discussion and agenda for future research", International Journal of Psychophysiology, 63(2), 199-204.

[29] Markus, H. R., \& Kitayama, S. (1991). Culture and the self: Implications for cognition, emotion, and motivation. Psychological Review, 98, 224-253.

[30] McConnon, A. and Stead, D.(2007), "If i only had a brain scan”, Business Week,4018(19), 22 January, p. 19.

[31] Macklem, K. (2005), "It's mind over money", Maclean's, 118(21), 66-8.

[32] Medina, J. (2004), "The neurobiology of the decision to buy", Psychiatric Times, October, 31-4.

[33] Moore, K. (2005), "Maybe it is like brain surgery”, Marketing 
Magazine, 110(15), p. 12.

[34] Mucha, T. (2005a), "This is your brain on advertising", Business, 6(7), 35-7.

[35] Mucha, T. (2005b), "Why the caveman loves the pitchman", Business 2.0, 6(3), 37-9.

[36] Nature Neuroscience (2004), “Brain scam?”, Nature Neuroscience, 7( 7), p. 683.

[37] Pettigrew, S., Roberts M, Chapman K, Quester P, Miller C., (2012) The use of negative themes in television food advertising, Appetite, 58, 469-503

[38] Perrachione, T. K. and J. R. Perrachione (2008). "Brains and brands: Developing mutually informative research in neuroscience and marketing." Journal of Consumer Behaviour 7(4-5): 303-318.

[39] Phan,V.(2010).Neuromarketing: Who decides what you buy?The Triple Helix.

[40] Pinker, S. (2002). The Blank Slate: The Modern Denial of Human Nature. New York: Viking; London: Penguin.

[41] Psychiatric Annals (2004), "Psychiatric Annals Biological branding: neuroimaging studies may form a basis for new marketing and advertising strategies", Psychiatric Annals, 34(9), 672-86.

[42] Rangel, A. (2004), "Book review of Paul Glimcher, Decisions, Uncertainity, and the Brain: The Science of Neuroeconomics", Journal of Economic Literature, 42,502-4.
[43] Renvoise, P. and Morin, C. (2005), Neuromarketing: Is There a Buy Button Inside the Brain?, Sales Brain Publishing, San Francisco, $C A$.

[44] Reynolds, J. (2006), "Editorial", Journal of Targeting, Measurement and Analysis for Marketing, 14(3), 189-90.

[45] Reid, A. (2005), "Neuromarketing", Campaign (UK), 49, 2 December, p. 10.

[46] Robison, J. (2006), "Is that a neuromarketer in your brain?", Gallup Management Journal, 12 January.

[47] Singer, E. (2004), "They know what you want", New Scientist, 183(2458), 36-7.

[48] Schafer, A. (2005), "Buy this", Scientific American Mind, $16(2), 72-5$

[49] Walton, C. (2004), "The brave new world of Neuromarketing is here", B\&T (Australia), 19 November, p. 22.

[50] www.startups.ro/analize/neuromarketingul-te-duce-in-minte a-consumatorilor - information retrieved on July 16, 2010.

[51] www.wisegeek.com/what-is-neuromarketing.htm information retrieved on Aug 3, 2013.

[52] www.neurosense.co.uk/ - information retrieved on Aug 3, 2013.

[53] www.neurosciencemarketing.com - information retrieved on Aug 3, 2013.

[54] www.neuromarketing.blogs.com - information retrieved on Aug 3, 2013. 